\title{
Erratum to: Effect of circulating tumor cells combined with negative enrichment and CD45-FISH identification in diagnosis, therapy monitoring and prognosis of primary lung cancer
}

\author{
Yang-Yang Chen ${ }^{1} \cdot$ Guo-Bin $\mathrm{Xu}^{1}$
}

Published online: 29 May 2015

(c) Springer Science+Business Media New York 2015

\section{Erratum to: Med Oncol (2014) 31:240}

\section{DOI 10.1007/s12032-014-0240-0}

There were errors in the abstract of the original publication. The penultimate sentence in the abstract should read as "Furthermore, PFS in patients whose post-treatment CTCs count increased or were unchanged accompanied by a baseline CTCs count $\geq 3$ was significantly shorter than those whose post-treatment CTCs count decreased or was unchanged accompanied with baseline value $C<3(1.85$ vs. 8.22 months, $p=0.000$ )".

The author regret the inconvenience caused to the readers in this regard.

The online version of the original article can be found under doi:10.1007/s12032-014-0240-0.

Guo-Bin Xu

cyyjyk@sina.com

1 Department of Clinical Laboratory, Peking University First Hospital, No. 8 XiShiKu Street, Xicheng District,

Beijing 100034, China 